\title{
ON JORDAN'S, REDHEFFER'S AND WILKER'S INEQUALITY
}

\section{BARKAT ALI BHAYO AND JÓZSEF SÁNDOR}

Abstract. In this paper, the authors offer new Jordan, Redheffer and Wilker type inequalities, along with refinements and converses. Connections with Euler's gamma function are pointed out, too.

Mathematics subject classification (2010): 26D05, 26D07, 26D99.

Keywords and phrases: Trigonometric and hyperbolic functions, Jordan's inequality, Cusa-Huygens inequality, Redheffer's inequality, Wilker's inequality and Becker-Stark inequality.

\section{REFERENCES}

[1] M. Abramowitz, And I. Stegun, eds., Handbook of mathematical functions with formulas, graphs and mathematical tables, National Bureau of Standards, Dover, New York, 1965.

[2] D. Aharonov, AND U. Elias, Improved inequalities for trigonometric functions via Dirichlet and Zeta functions, Math. Ineq. Appl. Vol. 16, no. 3 (2013), 851-859.

[3] H. Alzer, On some inequality of gamma and psi function, Math. Comp. Vol. 66, 217 (1997), 373389.

[4] G. D. Anderson, M. K. Vamanamurthy, And M. Vuorinen, Monotonicity Rules in Calculus, Amer. Math. Month. Vol. 113, No. 9 (2006), 805-816.

[5] G. D. Anderson, M. K. Vamanamurthy, And M. Vuorinen, Monotonicity of some functions in calculus, preprint, https://www.math.auckland.ac.nz/Research/Reports/Series/ 538.pdf.

[6] G. D. Anderson, M. Vuorinen, And X. Zhang, Topics in special functions III., http://arxiv.org/abs/1209.1696.

[7] Á. BARICZ, Redheffer Type Inequality for Bessel Functions, JIPAM. Vol. 8, 1, Art 11, 2007.

[8] M. BECKER, AND E. L. STRAK, On a hierarchy of quolynomial inequalities for $\tan (x)$, Univ. Beograd. Publ. Elektrotehn Fak Ser Mat Fiz. No. 602-633 (1978), 133-138.

[9] M. BIERNACKI, J. KRZYŻ, On the monotonicity of certain functionals in the theory of analytic functions, Ann. Univ. Mariae. Curie-Sklodowska 2 (1955) 134-145.

[10] C.-P. CHEN, J.-W. ZHAO, AND F. QI, Three inequalities involving hyperbolically trigonometric functions, RGMIA Res. Rep. Coll. 6 (3) (2003) 437-443. Art. 4.

[11] C.-P. CHEN, J. SÁNDOR, Inequality chains for Wilker, Huygens and Lazarević type inequalities, J. Math. Ineq. 7, 4 (2013), 569-575.

[12] L. Debnath, And C.-J. Zhao, New strengthened Jordan's inequality and its applications, Appl. Math. Lett., vol. 16, no. 4, 2003, pp. 557-560.

[13] B.-N. GUO, B.-M. QIAO, F. QI, AND W. LI, On new proofs of Wilker's inequalities involving trigonometric functions, Math. Ineq. Appl. 6 (2003), 19-22.

[14] W.-D. JiAng, AND H. Yun, Sharpening of Jordan's Inequality and its Applications, J. Ineq. Pure and Appl. Math. 7 (3) Art. 102, 2006.

[15] V. Heik kala, M. K. Vamanamurthy, and M. Vuorinen, Generalized elliptic integrals, Comput. Methods and Function Theory April 2009, Vol. 9, Issue 1, pp. 75-109.

[16] P. IVÁDY, On a beta function inequality, J. Math. Inequal. 6, 3 (2012), 333-341.

[17] A. JEFFrey, Handbook of Mathematical Formulas and Integrals, 3rd ed., Elsevier Academic Press, 2004.

[18] R. KlÉN, M. Visuri, AND M. VuORINEn, On Jordan type inequalities for hyperbolic functions, J. Ineq. Appl., vol. 2010, pp. 14. 
[19] J.-L. LI, AND Y.-L. LI, On the Strengthened Jordan's Inequality, J. Ineq. Appl. 2007, Art. ID 74328, pp. 8.

[20] L. Li, And J. Zhang, A new proof on Redheffer-Williams' inequality, Far East J. Math. Sci., 56 (2011), no. 2, 213-217.

[21] D. S. Mitrinović, Analytic Inequalities, Springer-Verlag, Berlin, 1970.

[22] C. Mortici, The natural approach of Wilker-Cusa-Huygens inequalities, Math. Inequal. Appl., 14, 3 (2011), 535-541.

[23] E. Neuman, Refinements and generalizations of certain inequalities involving trigonometric and hyperbolic functions, Advances in Inequalities and Applications, 1 (2012), No. 1, 1-11.

[24] E. Neuman, Inequalities Involving Hyperbolic Functions and Trigonometric Functions, Bull. Int. Math. Vir. Int. Vol. 2 (2012), 87-92.

[25] E. Neuman, AND J. SÁNDOR, On some inequalities involving trigonometric and hyperbolic functions with emphasis on the Cusa-Huygens, Wilker, and Huygens inequalities, Math. Inequal. Appl. Vol. 13, Number 4 (2010), 715-723.

[26] E. NeUmAn, AND J. SÁNDOR, Optimal inequalities for hyperbolic and trigonometric functions, Bull. Math. Anal. Appl. 3 (2011), no. 3, 177-181.

[27] A. Y. ÖZBAN, A new refined form of Jordan's inequality and its applications, Appl. Math. Lett., 19 (2006), 155-160.

[28] I. PINELIS, L'Hospital Rules for Monotonicity and the Wilker-Anglesio Inequality, Amer. Math. Monthly 111 (10) (2004), 905-909.

[29] F. QI, Extensions and sharpenings of Jordan's and Kober's inequality, Journal of Mathematics for Technology (in Chinese), 4 (1996), 98-101.

[30] R. RedhefFer, Problem 5642, Amer. Math. Monthly 76 (1969), 422.

[31] H. Rus KeEPÄ̈̈, Mathematica ${ }^{\circledR}$ Navigator, 3rd ed. Academic Press, 2009.

[32] J. SÁNDOR, On new refinements of Kober's and Jordan's trigonometric inequalities, Notes Number Theory Discrete Math. Vol. 19, 2013, No. 1, 73-83.

[33] J. SÁNDOR, Two sharp inequalities for trigonometric and hyperbolic functions, MIA 15 (2012), no. 2, 409-413.

[34] J. SÁndoR, Sharp Cusa-Huygens and related inequalities, Notes Number Theory Discrete Math. Vol. 19, 2013, No. 1, 50-54.

[35] J. SÁNDOR, AND R. OLÁH-GÁL, On Cusa-Huygens type trigonometric and hyperbolic inequalities, Acta Univ. Sapientiae, Mathematica, 4, 2 (2012) 145-153.

[36] J. SÁndor, AND M. Bencze, On Huygens' trigonometric inequality, RGMIA Res. Rep. Collection, 8 (2005), No. 3, Art. 14.

[37] J. SÁndor, On the concavity of $\sin (x) / x$, Octogon Math. Mag., 13 (2005), no. 1, 406-407.

[38] J. SÁNDOR, Trigonometric and hyperbolic inequalities, http://arxiv.org/abs/1105.0859.

[39] J. SÁNDOR, Some integral inequalities, Elem. Math. 43 (1988), 177-180.

[40] J. SÁndor, Sur la fonction Gamma, P.C.R. Math. Pures Neuchâtel, Serie I, 21(1989), 4-7.

[41] J. SÁNDOR, On the Gamma function II, P.C.R. Math. Pures Neuchâtel, Serie I, 28 (1997), 10-12.

[42] J. SÁNDOR, On the Open problem OQ. 532, Octogon Math. Mag. 9 (2001), No. 1B, 569-570.

[43] J. SÁNDOR, On the gamma function III, P.C.R. Math. Pures Neuchâtel, Série 2, 19 (2001), 33-40.

[44] J. S. Sumner, A. A. Jagers, M. Vowe, And J. Anglesio, Inequalities involving trigonometric functions, Amer. Math. Monthly 98 (1991), 264-267.

[45] J. SUn AND L. ZHU, Six new Redheffer-type inequalities for circular and hyperbolic functions, Comput. Math. Appl. 56, 2 (2008) 522-529.

[46] J. B. Wilker, Problem E3306, Amer. Math. Monthly 96 (1989) 55.

[47] J. P. Williams, Solution of problem 5642, Amer. Math. Monthly 76 (1969) 1153-1154.

[48] S.-H. WU AND H. M. SRIVASTAVA, A weighted and exponential generalization of Wilker's inequality and its applications, Integral Transforms and Spec. Funct. 18 (2007), No. 8, 525-535.

[49] S.-H. WU AND H. M. SRIVASTAVA, A further refinement of Wilker's inequality, Integral Transforms and Spec. Funct. 19 (2008), No. 10, 757-765.

[50] Z.-H. WANG, A new Wilker-type inequality, Journal of Yibing University, vol. 6, pp. 21-22, 2007.

[51] Z.-H. YANG, Refinements of a two-sided inequality for trigonometric functions, J. Math. Inequal., 7, 4 (2013) 601-615.

[52] L. Zhang AND L. ZHU, A new elementary proof of Wilker's inequalities, Math. Ineq. Appl. vol. 11, 2008, No. 1, 149-151. 
[53] L. ZHU, Sharpening Redheffer-type inequalities for circular functions, App. Math. Lett. 22 (2009), 743-748.

[54] L. ZHU, Sharpening Jordan's inequality and the Yang Le inequality, Appl. Math. Lett., 19 (2006), 240-243.

[55] L. ZHU, A new simple proof of Wilker's inequality, Math. Ineq. Appl., vol. 8 (2005), No. 4, 749-750.

[56] L. ZHU, On Wilker-type inequalities, Math. Ineq. Appl. Vol. 10 (2007) No. 4, 727-731.

[57] Z. SUn AND L. ZHU, On new Wilker-type inequalities, ISRN Math. Anal. Vol. 2011, Article ID 681702, 7 pp. 